\title{
Cytological diagnosis of Rosai-Dorfman disease: A case report and revision of the literature
}

\author{
RAQUEL GARZA-GUAJARDO ${ }^{1}$, LAURA ELVIRA GARCÍA-LABASTIDA ${ }^{1}$, \\ IRAM PABLO RODRÍGUEZ-SÁNCHEZ ${ }^{2}$, GABRIELA SOFÍA GÓMEZ-MACÍAS ${ }^{1}$, IVÁN DELGADO-ENCISO ${ }^{3}$, \\ MARÍA MARISELA SÁNCHEZ CHAPARRO ${ }^{4}$ and ORALIA BARBOZA-QUINTANA ${ }^{1}$
}

\begin{abstract}
${ }^{1}$ Department of Pathological Anatomy and Cytopathology, University Hospital 'Dr José Eleuterio González', Autonomous University of Nuevo León; ${ }^{2}$ Department of Genetics, School of Medicine, Autonomous University of Nuevo León, Monterrey, Nuevo Leon 64460; ${ }^{3}$ Universisy of Colima, School of Medicine, Colima 28030; ${ }^{4}$ Laboratory of Immunology and Virology, Faculty of Biological Sciences, Autonomous University of Nuevo León, San Nicolas de los Garza, Nuevo Leon 66420, Mexico
\end{abstract}

Received September 20, 2016; Accepted October 21, 2016

DOI: $10.3892 /$ br.2016.814

\begin{abstract}
Rosai-Dorfman disease also known as sinus histiocytosis with massive lymphadenopathy (SHML) is characterized by distorted lymph node architecture with marked dilation of lymphatic sinuses occupied by numerous lymphocytes, as well as histiocytes with vesicular nucleus and abundant clear cytoplasm with phagocytized lymphocytes or plasma cells, also known as 'emperipolesis'. This disease of unknown etiology progresses with a benign prognosis strictly and only when an early diagnosis and treatment is made. A late diagnosis and a generalized lymph node involvement contribute to a poor prognosis. In this study, we focussed on the cytological characteristics of the Rosai-Dorfman disease and differential diagnoses. We reported a case of a 61-year-old Mexican male with a 9-month history of painless bilateral cervical masses and low-grade fever with the final diagnosis of Rosai-Dorfman disease. The final diagnosis was made by fine needle aspiration (FNA) biopsy of parotid gland and cervical lymph node. In conclusion, FNA biopsy can be enough to make the diagnosis in most cases due to the distinct cytological features of SHML, thereby avoiding more invasive approaches that potentially are unnecessary.
\end{abstract}

\section{Introduction}

Sinus histiocytosis with massive lymphadenopathy (SHML) or Rosai-Dorfam disease is a rare self-limited and benign disease

Correspondence to: Dr Oralia Barboza-Quintana, Department of Pathological Anatomy and Cytopathology, University Hospital 'Dr José Eleuterio González', Autonomous University of Nuevo León, Francisco I. Madero y Gonzalitos S/N, Mitras Centro, Monterrey, Nuevo Leon 64460, México

E-mail: oralibarboza@gmail.com

Key words: Rosai-Dorfman disease, sinus histiocytosis, massive lymphadenopathy, fine needle aspiration biopsy that was first described in 1969 (1). The clinical features in the classical form include painless enlargement of cervical lymph nodes, fever, leukocytes, anemia, hypergammaglobulinemia and elevated erythrocyte sedimentation (2). Frequently other lymph nodes can be involved such as axillary, paraaortic, mediastinal, inguinal (3) and concurrent extranodal disease may be evident. Extranodal disease has a particular predilection for the head and neck region (75\% of cases) (4). Involvement of $\geq 1$ extranodal site has been identified in $43 \%$ of cases and only $23 \%$ have extranodal disease exclusively $(1,5)$. Documented sites of extranodal involvement include skin, respiratory tract, bone, genitourinary system, oral cavity, central nervous system, eyes and ocular adnexa, salivary gland, tonsil, breast, soft tissue and heart (6-9). This condition can occur at any age, albeit $80 \%$ of the patients are aged 20 years or younger at onset, with a higher prevalence in males $(8,10,11)$.

The etiology of the disease is unknown but several theories have been suggested. Some infectious agents have been suspected, includig Epstein-Barr virus (12), Parvovirus B19 (13), Herpes virus type 6 and $8(14,15)$ and Polyomavirus (16). A relationship with Klebsiella, Brucella and Cytomegalovirus was also suggested, but any attempt to isolate the organisms consistently failed (12). Other proposed mechanisms include immune dysfunction or an aberrant exaggerated immune response to an infectious agent or an antigen that causes a proliferation of histiocytes (6). Stimulation of monocytes/macrophage via macrophage colony-stimulating factor was also involved (17). These mechanisms suggest an immune misrregulation (18). In addition, $10-12 \%$ of patients with SHML exhibit autoimmune phenomena $(19,20)$.

The classical histology of this entity is characterized by distorted nodular architecture with marked dilation of lymphatic sinuses, partial effacement of follicles and germinal centers, as well as capsular and pericapsular fibrosis (1). Lymphatic sinuses are occupied by numerous lymphocytes and histiocytes with vesicular nucleus and abundant clear cytoplasm with phagocytized lymphocytes or plasma cells, also known as 'emperipolesis' $(5,6,21)$.

Immunohistochemical analysis revealed the cells were positive for protein S-100, but typically negative for CD1a. 
These cells also expressed $\alpha$-1-antitrypsine and other pan-macrophage antigens (CD68 and HAM56) (22). The cytological characteristics of SHML are highly distinctive. Consequently, fine needle aspiration (FNA) biopsy may be sufficient to make the diagnosis in most cases thus preventing unnecessary invasive procedures $(5,6,21,22)$.

\section{Case presentation}

In the current study, we present a 61-year-old Hispanic (Mexican) male patient seen on the Internal Medicine consult with a 9-month history of low-grade fever and painless bilateral cervical masses. On physical examination we found bilateral cervical and right supraclavicular adenopathy accompanied by an enlargement of the two parotid glands (Fig. 1). Laboratory exams showed anemia and high erythrocyte sedimentation rate. As the initial suspected diagnosis was a probable lymphoma a FNA biopsy was performed on a cervical node and parotid gland.

The patient's samples were stained to describe morphologic differences by Papanicolaou (Pap) and Diff-Quik stain techniques. The microscopic examination revealed a highly cellular sample with abundant histiocytes with large eosinophilic cytoplasm, in a reactive lymphocytic background, made up of lymphocytes, plasma cells, and few eosinophils and neutrophils. The cytoplasm of these histiocytes has numerous intact lymphocytes and plasma cells (Figs. 2 and 3). These findings were constant on the parotid gland and node. Finally, we evaluated a cellular block stained with hematoxylin and eosin and observed the classic histopathological charateristics of this disease as, distorted node architecture with marked dilation of sinuses and partial effacement of follicles and germinal centers. The sinuses are occupied by numerous histiocytes with a vesicular nucleus and abundant clear cytoplasm with phagocytized intact lymphocytes, known as 'emperopolesis' (Fig. 4). Following immunohistochemical analysis, the cells were found to be positive for CD68 and negative for CDla.

\section{Discussion}

As in histology, cytology from FNA biopsy is usually highly cellular, with numerous histiocytes with vesicular nucleus and abundant clear cytoplasm with fine vacuoles and lymphophagocytosis in a reactive background of lymphocytes, plasma cells and occasionally neutrophils $(5,10,23)$. Lymphatic sinuses are occupied by numerous lymphocytes and histiocytes with vesicular nucleus and abundant clear cytoplasm with phagocytized lymphocytes, neutrophils or plasma cells, also known as 'emperopolesis' $(5,6)$.

The chromatin of the histiocytes was satisfactory and evenly distributed, although the nuclear shapes varied from round to extremely bizarre configurations. The nucleoli are usually not prominent (24). Occasionally, atypical morphology may be seen and, when present, it can lead to a misdiagnosis of malignancy (25). Large binucleated and multinucleated forms were also present (21). Immunohistochemistry revealed the cells were positive for protein S-100, $\alpha$-1-antitrypsine and pan-macrophage antigens (CD68 and HAM56), but typically negative for CD1a $(6,22)$.

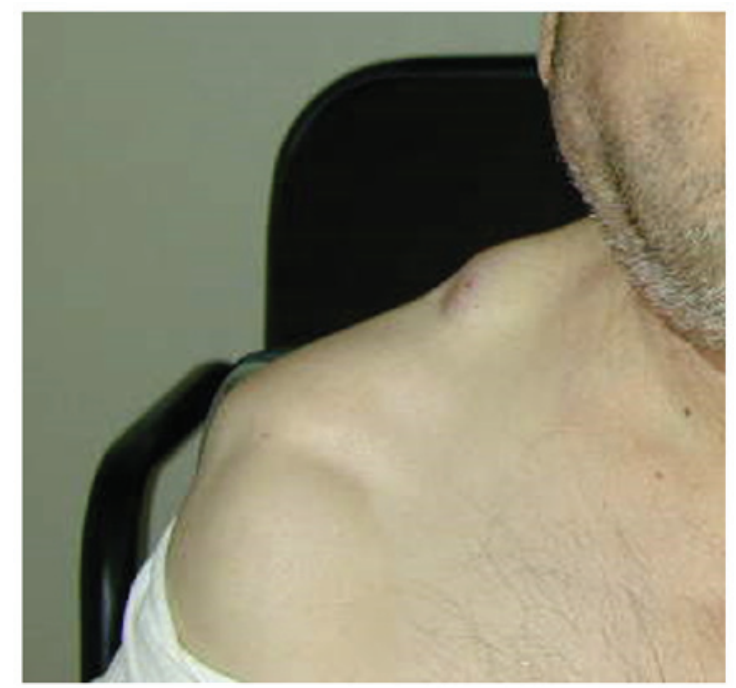

Figure 1. Appearance of the patient. Note the swelling of the parotid and supraclavicular lymph node enlargement.

Although the cytomorphological features may be well defined, diagnosis of SHML can be difficult to make, particularly in extranodal sites (23). Shi et al (5) reviewed 49 cases of Rosai-Dorfman disease diagnosed with FNA cytology, and found a significant misdiagnosis of SHML by FNA more often in extranodal rather than in nodal disease: $12 \%$ (3 out of 25) misdiagnosed cases in lymph node aspirations vs. $50 \%$ (6 out of 12) misdiagnosed or inconclusive cases in extranodal aspirations. In addition, diagnosis requires correlation with an appropriate clinical history.

In our case SHML is likely to be mistaken for lymphoma because of its typical presentation as a painless and bilateral cervical lymphadenopathy accompanied by non-specific signs of immune activation, occasional fever, neutrophilia and a high erythrocyte sedimentation rate. Therefore, SHML should be considered in the differential diagnosis of painless, unilateral or bilateral cervical lymphadenopathy, usually of marked size (10).

The differential cytological diagnosis includes reactive lymph node hyperplasia, infectious lymphadenitis, hemophagocytic syndrome, Langerhans cell histiocytosis, tuberculosis, and lymphoma (23-26). The main differential diagnoses are summarized in Table I. In the lymph node reactive hyperplasia there are sinusoidal hyperplasia with loose clusters of histiocytes, accompanying lymphocytes, germinal center cells, immunoblasts, and tingible body macrophages; however cytology usually does not show extensive emperipolesis while protein S-100 is negative. Techniques such as Pap and Diff-Quik staining, allow us to observe cellular differentiation between normal and squamous cells, as well as various features. In the case of SHML, techniques last mentioned help improve the cytological characterization.

Mallick et al (24) carried out a cytomorphological and morphometric analysis of 22 cases of SHML, and the authors quantified and compared the cell dimensions and nuclear dimensions of SHML histiocytes with those in the reactive lymph nodes. Morphometric parameters show the mean nuclear diameter of the SHML histiocytes was 
A

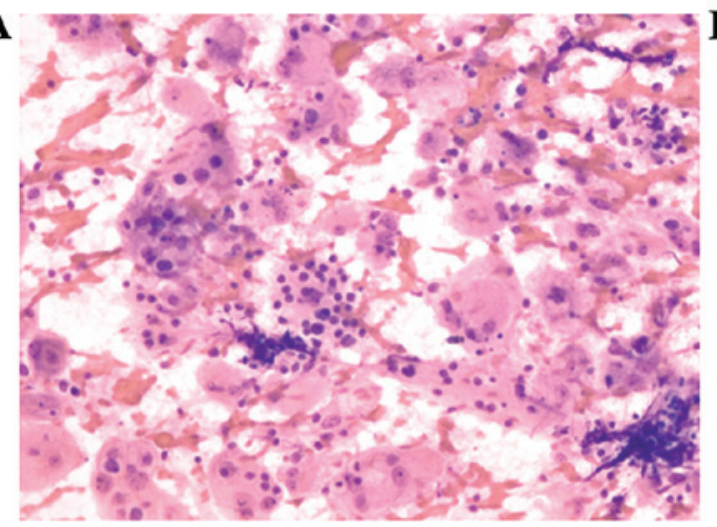

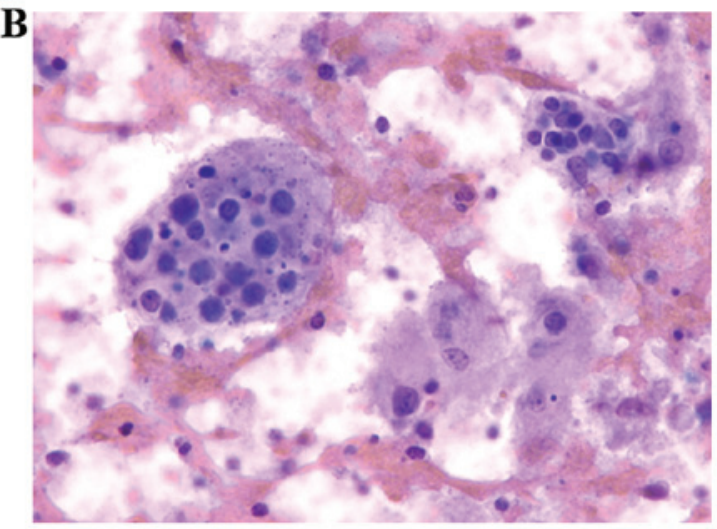

Figure 2. (A) Medium-power (magnification, x10) stained with the Papanicolaou technique. Hemorrhagic and lymphocytic background of chronic non-specific lymphadenitis, with large macrophages, with abundant cytoplasm and numerous lymphocytes are observed inside. (B) At higher magnification (magnification, $\mathrm{x} 40$ ) histiocytes with abundant clear or eosinophilic cytoplasm filled with many intact lymphocytes and plasma cells.
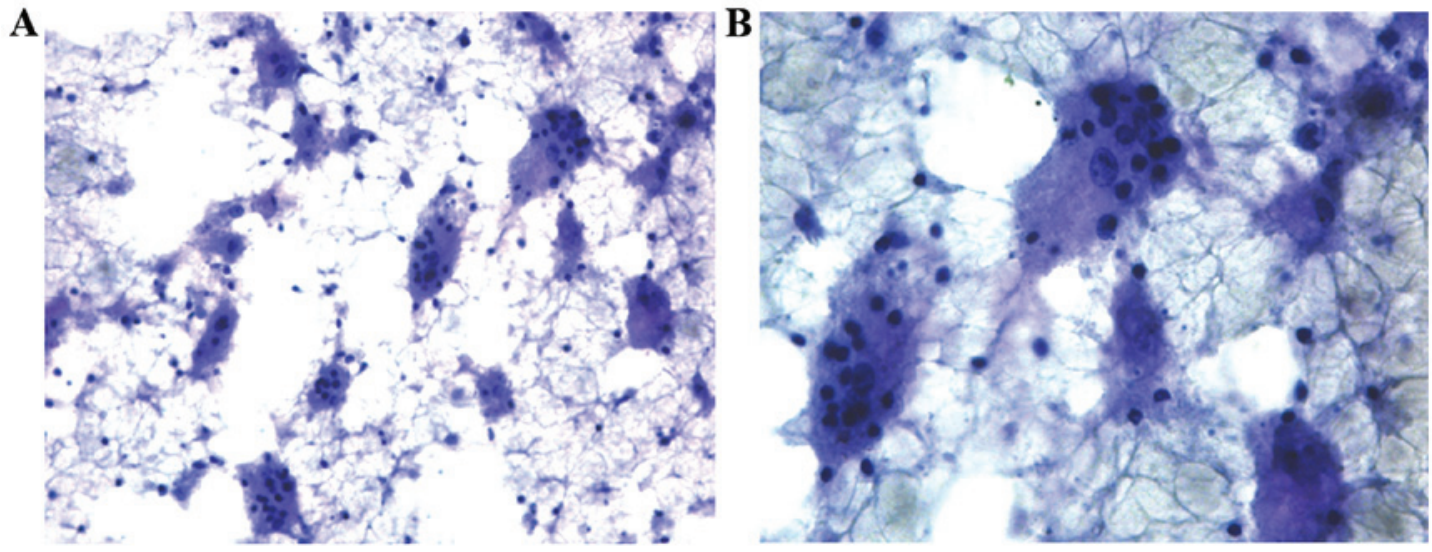

Figure 3. Same characteristics as Fig. 2, but evaluated with the Diff-Quik stain. [(A) Magnification, x10; and (B) magnification, x40].

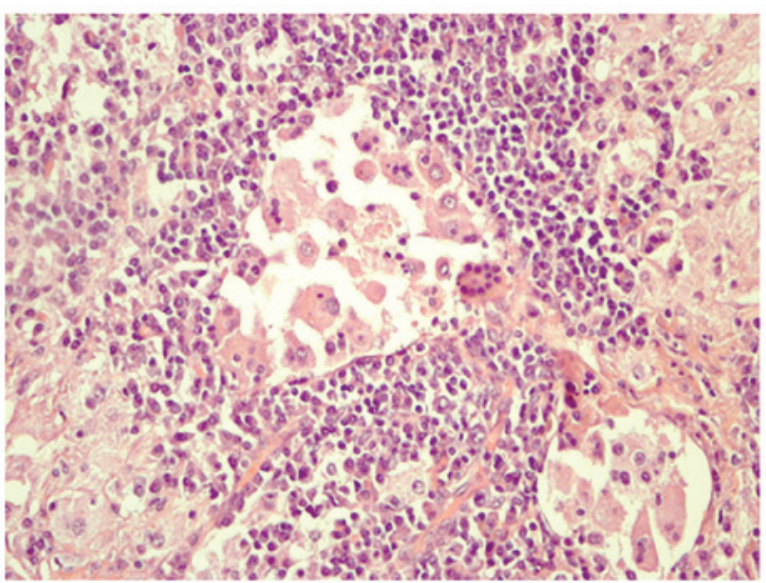

Figure 4. Cellular block with hematoxylin and eosin technique at medium power (magnification, x10). Fragment of a lymph node with important sinusoidal dilatation, note the histiocytes lining the sinuses. Many of the histiocytes have intact lymphocytes within their cytoplasm an important diagnostic feature known as emperipolesis.

$16.7 \mu \mathrm{m}$ compared with the diameter of reactive histiocytes at $10.1 \mu \mathrm{m}$, which was statistically significant $(\mathrm{P}<0.01)$. The median nuclear area in SHML histiocytes was $163.4 \mu \mathrm{m}^{2}$ and in reactive histiocytes it was $66.14 \mu \mathrm{m}^{2}$, which was statistically significant $(\mathrm{P}<0.001)$. SHML histiocytes were also significantly greater in size $(\mathrm{P}<0.001)$ than those in the reactive lymph nodes (24).

Hemophagocytic syndromes should be differentiated from Rosai-Dorfman disease on the basis of the presence of hemophagocytosis and absence of emperipolesis. This syndrome has a high association with hemathopoyetic malignancy and infectious processes and it is presented as systemic failure, frequently with pancytopenia and hepatosplenomegaly. Under microscopic examination, the most relevant, is the phagocytosis of red cells by histiocytes $(6,27)$. In Langerhans cell histiocytosis, Langerhans cells have grooved and twisted nuclei and the background has eosinophilic microabscess. Langerhans cells also express CD1a (28).

Following microscopy, we identified tuberculous lymphadenitis and other granulomatous lymphadenitis with cohesive aggregates of epithelioid histiocytes, frequently with associated necrosis but with a lack of phagocytized lymphocytes. Aggregates of epithelioid histiocytes were absent in Rosai-Dorfman disease $(26,29)$. Smears from patients with Hodgkin lymphoma show lymphocytes, plasma cells, histiocytes, eosinophils, and Reed-Sternberg cells (30). In non-Hodgkin lymphoma the most important cytological feature is the monomorphic population of lymphoid cells (31). Additionally, none of the previously described conditions is 
Table I. Common differential diagnoses for Rosai-Dorfman disease and their cytologic characteristics compared against other similar diseases.

\begin{tabular}{|c|c|c|c|}
\hline Entity/Disease & Cytology & Immunohistochemistry & Clinical features \\
\hline $\begin{array}{l}\text { Rosai Dorfman } \\
\text { disease }\end{array}$ & $\begin{array}{l}\text { Histiocytes with vesicular } \\
\text { nucleus and abundant clear } \\
\text { cytoplasm with fine vacuoles } \\
\text { and phagocytosed lymphocytes } \\
\text { and a reactive background } \\
\text { with abundant lymphocytes, } \\
\text { plasma cells and occasionally } \\
\text { neutrophils }\end{array}$ & $\begin{array}{l}\text { S-100 and CD68 expression } \\
\text { Negative for CD1a }\end{array}$ & $\begin{array}{l}\text { Affects children and young adults. More } \\
\text { common in males. Big but painless } \\
\text { adenopathies. They can present in } \\
\text { extranodal sites, usually head and neck }\end{array}$ \\
\hline $\begin{array}{l}\text { Sinusal hyperplasia } \\
\text { of lymph node }\end{array}$ & $\begin{array}{l}\text { Extended neutrophils, histiocytes } \\
\text { can or cannot be present } \\
\text { Phagocytosed lymphhocytes or } \\
\text { emperipolesis are not common }\end{array}$ & $\begin{array}{l}\text { Sinusoidal histiocytes } \\
\text { negative for S-100 }\end{array}$ & $\begin{array}{l}\text { Malaise and general symptoms, painless } \\
\text { adenopathies } \\
\text { Self-limited disease }\end{array}$ \\
\hline $\begin{array}{l}\text { Langerhans cell } \\
\text { histiocytosis }\end{array}$ & $\begin{array}{l}\text { Polymorphic infiltrate with } \\
\text { eosinophils and histiocytes } \\
\text { with cleaved nucleus }\end{array}$ & CD1a positive & $\begin{array}{l}\text { Variable clinical picture with single or } \\
\text { multiple lesions or disseminated disease. } \\
\text { Nodal involvement may be the sole } \\
\text { manifestation of disease or it can be } \\
\text { associated with systemic disease }\end{array}$ \\
\hline $\begin{array}{l}\text { Hemophagocytic } \\
\text { lymphohistiocytosis }\end{array}$ & $\begin{array}{l}\text { Benign histiocytes engulfing } \\
\text { erythrocytes and platelets }\end{array}$ & CD68 positive & $\begin{array}{l}\text { Associated to malignacy, mainly of } \\
\text { hemathological origin and to infections. } \\
\text { Manifested by multiple organ failure, } \\
\text { pancytopenia, and hepatosplenomegaly }\end{array}$ \\
\hline $\begin{array}{l}\text { Non-Hodgkin } \\
\text { lymphoma }\end{array}$ & $\begin{array}{l}\text { Monomorphic population of } \\
\text { lymphoid cells }\end{array}$ & $\begin{array}{l}\text { Variable depending on cell } \\
\text { line }\end{array}$ & $\begin{array}{l}\text { Adenopathies. Weight loss and general } \\
\text { symptoms can or cannot be present } \\
\text { may or may not have general symptoms }\end{array}$ \\
\hline Hodgkin lymphoma & $\begin{array}{l}\text { Polymorphic background with } \\
\text { small lymphocytes and } \\
\text { eosinophils with the presence } \\
\text { of Reed-Sternberg cells }\end{array}$ & $\begin{array}{l}\text { Reed-Sternberg cells } \\
\text { positive for CD } 15 \text { and CD } 30\end{array}$ & Adenopathies and B symptoms \\
\hline
\end{tabular}

characterized by a prominent emperipolesis, as was observed in SHML.

Most patients with SHML have spontaneous remission and some can recur or have persistent disease with asymptomatic but persistent lymphadenopathy. In very few cases it progresses to an aggressive tumor and can be fatal. Involvement of extranodal sites generally carries a poorer prognosis, and disease tends to be chronic and relapsing $(2,10)$. A poorer prognosis has been associated with dissemination and involvement of kidney, upper respiratory airway, liver and patients with underlying immune abnormalities or anemia (20). Death occurs in approximately $7 \%$ of patients, linked to a possible defect in the immune system (32).

An ideal treatment for SHML remains to be identified; nevertheless, approximately $50 \%$ of the patients require treatment. The management options range from observation for those patients with mild manifestations with no functional or cosmetic abnormalities to surgical resection, systemic steroids and in some cases chemo- or radiotherapy for patients with severe symptoms, as well as compromise of vital organs $(33,34)$.

In conclusion, the cytological features of SHML are distinctive in the correct clinical context, whereby biopsy with FNA may be sufficient for diagnosis in most cases, thus preventing unnecessary invasive approaches. Surgical resection for histological diagnosis should be considered in cases with inconclusive cytological findings, or unusual clinical presentation.

\section{Acknowledgements}

The authors acknowledge the critical reading of the manuscript by Dr Sergio Lozano.

\section{References}

1. Foucar E, Rosai J and Dorfman R: Sinus histiocytosis with massive lymphadenopathy (Rosai-Dorfman disease): Review of the entity. Semin Diagn Pathol 7: 19-73, 1990.

2. Gaitonde S: Multifocal, extranodal sinus histiocytosis with massive lymphadenopathy: An overview. Arch Pathol Lab Med 131: 1117-1121, 2007.

3. Najafi-Sani M, Saneian H and Mahjoub F: Rosai-Dorfman disease with nodal and extranodal involvements: A case report. J Res Med Sci 16: 1251-1256, 2011.

4. Cocker RS, Kang J and Kahn LB: Rosai-Dorfman disease. Report of a case presenting as a midline thyroid mass. Arch Pathol Lab Med 127: e197-e200, 2003

5. Shi Y, Griffin AC, Zhang PJ, Palmer JN and Gupta P: Sinus histiocytosis with massive lymphadenopathy (Rosai-Dorfman Disease): A case report and review of 49 cases with fine needle aspiration cytology. Cytojournal 8: 3, 2011. 
6. Kumar B, Karki S and Paudyal P: Diagnosis of sinus histiocytosis with massive lymphadenopathy (Rosai-Dorfman disease) by fine needle aspiration cytology. Diagn Cytopathol 36: 691-695, 2008

7. Vemuganti GK, Naik MN and Honavar SG: Rosai Dorfman disease of the orbit. J Hematol Oncol 1: 7, 2008.

8. Kala C, Agarwal A and Kala S: Extranodal manifestation of Rosai-Dorfman disease with bilateral ocular involvement J Cytol 28: 131-133, 2011.

9. Sandoval-Sus JD, Sandoval-Leon AC, Chapman JR Velazquez-Vega J, Borja MJ, Rosenberg S, Lossos A and Lossos IS: Rosai-Dorfman disease of the central nervous system: Report of 6 cases and review of the literature. Medicine (Baltimore) 93: $165-175,2014$.

10. Ruggiero A, Attinà G, Maurizi $P$, Mulè A, Tarquini E, Barone G, Lazzareschi I and Riccardi R: Rosai-Dorfman disease: Two case reports and diagnostic role of fine-needle aspiration cytology. J Pediatr Hematol Oncol 28: 103-106, 2006.

11. Jani PA and Banjan D: A case of sinus histiocytosis with massive lymphadenopathy (Rosai-Dorfman syndrome) from western India. Mcgill J Med 11: 156-159, 2008.

12. Tsang WY, Yip TT and Chan JK: The Rosai-Dorfman disease histiocytes are not infected by Epstein-Barr virus. Histopathology 25: 88-90, 1994.

13. Mehraein Y, Wagner M, Remberger K, Füzesi L, Middel P, Kaptur S, Schmitt K and Meese E: Parvovirus B19 detected in Rosai-Dorfman disease in nodal and extranodal manifestations. J Clin Pathol 59: 1320-1326, 2006.

14. Arakaki N, Gallo G, Majluf R, Diez B, Arias E, Riudavets MA and Sevlever G: Extranodal rosai-dorfman disease presenting as a solitary mass with human herpesvirus 6 detection in a pediatric patient. Pediatr Dev Pathol 15: 324-328, 2012.

15. Ortonne N, Fillet AM, Kosuge H, Bagot M, Frances C and Wechsler J: Cutaneous Destombes-Rosai-Dorfman disease: Absence of detection of HHV-6 and HHV-8 in skin. J Cutan Pathol 29: 113-118, 2002.

16. Al-Daraji W, Anandan A, Klassen-Fischer M, Auerbach A, Marwaha JS and Fanburg-Smith JC: Soft tissue Rosai-Dorfman disease: 29 new lesions in 18 patients, with detection of polyomavirus antigen in 3 abdominal cases. Ann Diagn Pathol 14: 309-316, 2010

17. Middel P, Hemmerlein B, Fayyazi A, Kaboth U and Radzun HJ: Sinus histiocytosis with massive lymphadenopathy: Evidence for its relationship to macrophages and for a cytokine-related disorder. Histopathology 35: 525-533, 1999.

18. Huang Q, Chang KL and Weiss LM: Extranodal Rosai-Dorfman disease involving the bone marrow: A case report. Am J Surg Pathol 30: 1189-1192, 2006

19. Grabczynska SA, Toh CT, Francis N, Costello C and Bunker CB Rosai-Dorfman disease complicated by autoimmune haemolytic anaemia: Case report and review of a multisystem disease with cutaneous infiltrates. Br J Dermatol 145: 323-326, 2001.

20. Maric I, Pittaluga S, Dale JK, Niemela JE, Delsol G, Diment J, Rosai J, Raffeld M, Puck JM, Straus SE, et al: Histologic features of sinus histiocytosis with massive lymphadenopathy in patients with autoimmune lymphoproliferative syndrome. Am J Surg Pathol 29: 903-911, 2005.
21. Juskevicius R and Finley JL: Rosai-Dorfman disease of the parotid gland: Cytologic and histopathologic findings with immunohistochemical correlation. Arch Pathol Lab Med 125: 1348-1350, 2001.

22. Panikar N and Agarwal S: Salivary gland manifestations of sinus histiocytosis with massive lymphadenopathy: Fine-needle aspiration cytology findings. A case report. Diagn Cytopathol 33: 187-190, 2005.

23. Pettinato G, Manivel JC, d'Amore ES and Petrella G: Fine needle aspiration cytology and immunocytochemical characterization of the histiocytes in sinus histiocytosis with massive lymphadenopathy (Rosai-Dorfman syndrome). Acta Cytol 34: 771-777, 1990.

24. Mallick S, Ghosh R, Iyer VK, Jain D and Mathur SR: Cytomorphological and morphometric analysis of 22 cases of Rosai-Dorfman disease: A large series from a tertiary care centre. Acta Cytol 57: 625-632, 2013.

25. Deshpande V and Verma K: Fine needle aspiration (FNA) cytology of Rosai Dorfman disease. Cytopathology 9: 329-335, 1998.

26. Kushwaha R, Ahluwalia C and Sipayya V: Diagnosis of sinus histiocytosis with massive lymphadenopathy (Rosai-Dorfman Disease) by fine needle aspiration cytology. J Cytol 26: 83-85, 2009.

27. Zeppa P, Vetrani A, Ciancia G, Cuccuru A and Palombini L: Hemophagocytic histiocytosis diagnosed by fine needle aspiration cytology of the spleen. A case report. Acta Cytol 48: 415-419, 2004.

28. Sachdev R and Shyama J: Co-existent Langerhans cell histiocytosis and Rosai-Dorfman disease: A diagnostic rarity. Cytopathology 19: 55-58, 2008.

29. Cozzolino I, Scognamiglio G, Sosa Fernandez LV and Zeppa P: Lymph nodes Fine Needle Cytology in the diagnosis of infectious diseases: Cytological and histological correlations. Infez Med 20 (Suppl 3): 16-20, 2012.

30. Chhieng DC, Cangiarella JF, Symmans WF and Cohen JM: Fine-needle aspiration cytology of Hodgkin disease: A study of 89 cases with emphasis on false-negative cases. Cancer 93: 52-59, 2001.

31. Bangerter M, Brudler O, Heinrich B and Griesshamnuer M: Fine needle aspiration cytology and flow cytometry in the diagnosis and subclassification of non-Hodgkin's lymphoma based on the World Health Organization classification. Acta Cytol 51: 390-398, 2007.

32. Zhu F, Zhang JT, Xing XW, Wang DJ, Zhu RY, Zhang Q, Wang HT and Lang SY: Rosai-Dorfman disease: A retrospective analysis of 13 cases. Am J Med Sci 345: 200-210, 2013.

33. Córdova Ramos G, Machin González V and Benítez Tang SM: Rosai-Dorfman's disease: A propos of an interesting case study. Acta Otorrinolaringol Esp 59: 311-313, 2008 (In Spanish).

34. Chen J, Tang H, Li B and Xiu Q: Rosai-Dorfman disease of multiple organs, including the epicardium: An unusual case with poor prognosis. Heart Lung 40: 168-171, 2011. 